\title{
Methodology for Selecting Thermoelectric Module for Portable Vaccine Cold Box
}

\author{
Banoth Srinu $^{1}$ and Jaya Krishna Devanuri ${ }^{2}$ \\ ${ }^{1}$ Mechanical Engineering Department,Indian Institute of Information Technology - Design and Manufacturing, \\ Kancheepuram, Tamil Nadu , India \\ ${ }^{2}$ Mechanical Engineering Department,National Institute of Technology, Warangal, Telangana, India \\ E-Mail:mfd15i017@iiitdm.ac.in,djayakrishna@nitw.ac.in
}

\begin{abstract}
Vaccine cold boxes are used for storing as well as transporting vaccine at precisely controlled temperature range. The aim of this paper is to define a design methodology in selecting a thermoelectric module (TEM) for a portable vaccine cold box that maintainsan internal temperature between $2-7^{\circ} \mathrm{C}$. A Cold box is designed based on the principle of thermoelectric effects (i.e. Peltier effect) wherethe cold side of the TEM is attached to the cold box for extracting the heat load and maintain the required temperature range inside it. The heat from the hot side is ejected to surrounding with the help of heat sinks and fans for the enhancement of thermoelectric performance. The study provides the methodology for the selection of available Peltier's and usage of these Peltier's in the design of cold box. Based on the study it is observed that the minimum temperature in the vaccine box can be reached to $5^{\circ} \mathrm{C}$ which indicates that the vaccine cold box can be maintained at desired temperature.
\end{abstract}

Keywords : Thermoelectric module, Peltier effect, vaccine cold box

\section{INTRODUCTION}

Vaccination is the highly effective method for preventing many infectious diseases. Routine immunization protects most of the world's children from the diseases that claim millions of lives each year. In 2016, World Health Organization estimated about 19.5 million infants worldwide were not reached with routine immunization services such as DTP3 vaccine. It is estimated that almost 60 percent of the children live in countries like Angola, Brazil, Pakistan and South Africa, India, Indonesia, Iraq and Nigeria could not undergo immunization due to:

1. Destroyed or unreliable transport infrastructure.

2. Insufficient and/or inoperable cold chain equipment.

3. Lack of sufficiently trained technical staff.

4. Insecurity due to ongoing conflict, mines.[1]

The most common cooling system utilized for cooling vaccine and clinical transplantation is done by vapor compression refrigeration (VCR) system. The VCR system consists of parts like evaporator, compressor, condenser tube and throttle valve. However, this system is heavy, costly and noisy and also results in the emissions like greenhouse and Chloro-fluoro carbons. These emissions result in ozone layer depletion and causes increase in the global temperature. Other method is by placingin the insulated box surrounded with ice in which sterilization of the organs and medical elements will be difficult as they need proper maintenance of the temperature.[2][3]

To overcome these difficulties implementation of portable, noise free, ecofriendly for safe transportation of organs and medical elements is necessary.The present study aims to design a cold box that can maintain a temperature around 2$\left.8^{\circ} \mathrm{q} 4\right]$. The minimum required temperature range inside the cold box thermoelectric modules are used and heat is rejected to the surroundings which is at a temperature of 3540.

\section{A. Peltier effect}

Peltier effect occurs whenever the electrical current flows through the dissimilar semiconductors. The heat at the junction is either absorbed or released depending upon the direction of the flow of the current[5].

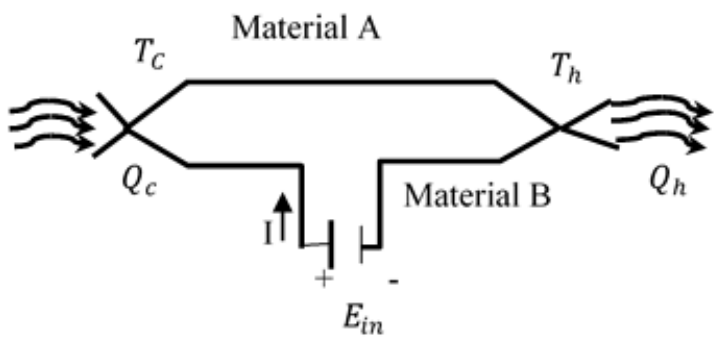

Fig. 1 Peltier effect

\section{Thermoelectric operation}

If the voltage $\mathrm{E}_{\mathrm{in}}$ is applied to the junction and electric current $I$ flows through the closed circuit as a result the cooling effect occurs at the junction where heat absorption takes place and heating effect at the opposite junction. Figure 1 shows the Peltier with hot and cold junction.It can be noted that joule heating also occurs in the conductor as a result of current flow with a magnitude of $I^{2} R$ (where $R$ is electrical resistance). The heat flow occurs in opposite direction of Peltier effect and cause reduction in the cooling effect[6].

Bismuth and telluride are the materials of choice for the semiconductors in the thermo-electrical module as they can 
be easily optimized for the pumping heat. Also, the designers have the flexibility in control type of charge carriers employed within semiconductors. In the module, $\mathrm{P}$ and $\mathrm{N}$ semiconductors are connected thermally in parallel and electrically in series. As shown in Figure 2, throughout the circuit, the heat moves on the direction of the charge carriers flow throughout the circuit. The aim of present study is to select appropriate thermoelectric module for a portable vaccine cold box to maintain the temperature of 2$8^{\circ} \mathrm{C}$ by removing heat load from the cabin. Therefore the study presents the methodology for the selection of a suitable Peltier module to maintain a cold box between 2-8.

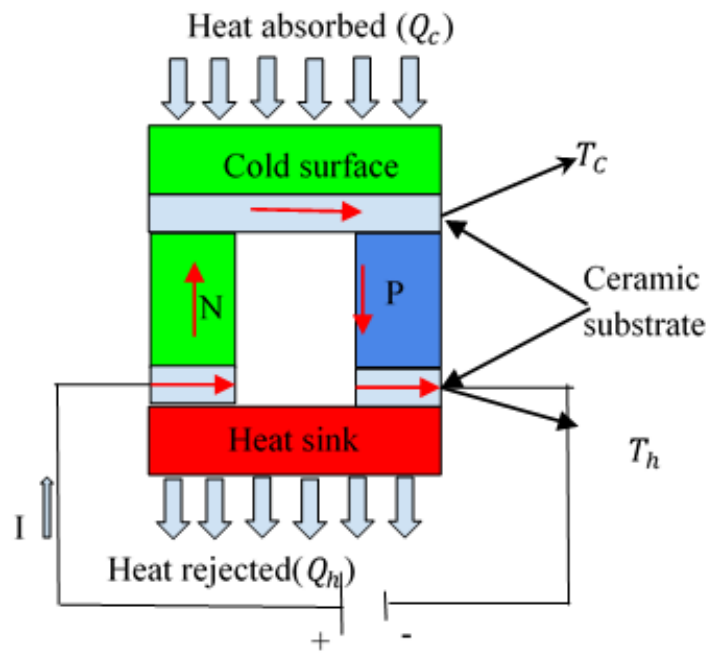

Fig 2Thermoelectric cooling

\section{METHODOLOGY FOR SELECTION OF THERMOELECTRIC MODULE}

Proper selection of the thermoelectric module is critical to the performance of the thermoelectric cooler. Selection of thermoelectric modules to pump a certain amount of heat at a given voltage and current depends on several factors, but the three important parameters of them are:

1. Temperature at the hot end of the module $\left(T_{h}\right)$.

2. Temperature at the cold end of the module $\left(T_{C}\right)$.

3. Heat load to be absorbed at the cold end of the module $\left(Q_{c}\right)$. The hot side of the module is the side where heat is released when DC power is applied and heat sink is attached to this side. By using an air cooled heat sink (natural or forced convection) the hot side temperature and heat transferred can be found by the Eqs(1) and (2).

$T_{h}=T_{a m b}+R \times Q_{h}$

$Q_{h}=Q_{c}+P_{\text {in }}$

\section{Heat load estimation}

Estimating amount of the heat load to be absorbed at the cold end is an important aspect for the selection of the module. The thermal load in the cooling system can be broadly classified into
a. Active load
b. Passive load

\section{Active load}

Active load is the actual heat load generated by the component or the system to be cooled. For the most of the applications the active load is equal to the electrical input power.

The general equation for active load power dissipation is $Q_{\text {active }}=\frac{V^{2}}{R}=I^{2} \times R$

Generally, many thermoelectric applications do not have active loads and this can be completely neglected.

\section{Passive load}

Passive heat load is the heat lost or gained by the cold box that is dissipated in/out due to convection, conduction and radiation. Passive heat loss may occur through the conductive path including insulation, electrical wiring and infiltration of air. The heat load by including both conduction and convection can be given by Eq (4)

$Q=\frac{A \times \Delta T}{\frac{1}{h}+\frac{L}{k}}$

\section{B. Heat sink}

The heat from the cabin being cooled is passed from the inside cold face to the outside hot face. To accomplish this system, the hot face of the thermoelectric module must to be attached with suitable heat sink. The heat sink should be capable of dissipating the heat pumped by the module and the joule heat created as a result of supplying electrical energy through the thermoelectric module.Thermal resistance of the heat sink can be given as,[7]

$R=\frac{\Delta T}{Q}$

\section{Thermoelectric module selection}

It is required to choose the thermoelectric module that not only has sufficient cooling capacity but should also meet the dimensional requirements for housing whichcan maintain required temperature in the cold box.

Thermoelectric module can be selected based on the following parameters, i) heat load to be removed $\left(Q_{c}\right)$, temperature difference between the hot and cold end of the module $(\Delta T)$ and maximum possible temperature ( $\left.T_{\max }\right)$.

$\Delta T=T_{h}-T_{c}$

$\Delta T_{\max }=\frac{\alpha^{2}\left(T_{c}\right)^{2}}{2 k R}$

During the operation the DC power flows through the module causing the heat to transfer from one side to another creating hot and cold side of the module. A single stage Peltier module can achieve maximum temperature change about $68^{\circ} \mathrm{C}[8]$.Also, the maximum current $\left(I_{\max }\right)$ for maximum absorption of heat load can be given as,

$I_{\max }=\frac{\alpha \cdot T c}{R}$

Where 
Resistance $R=\frac{\rho . L e}{A e}$

Once the ratio of $\Delta T / \Delta T_{\max }$ and $I / I_{\max }$ are suitablebased on the values the cooling rate can be obtained.

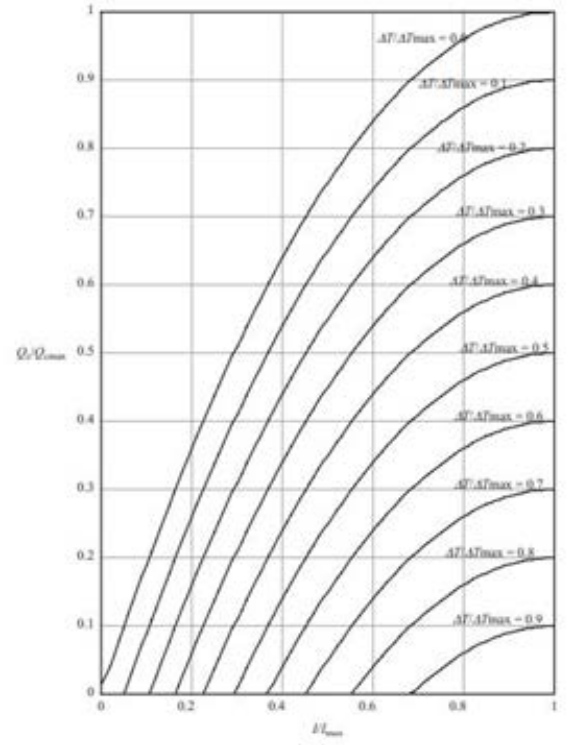

Fig 3. Generalized charts of cooling rate ratio vs. current ratio for a singlestage Peltier module (independent of $Z T_{c}$ ) [9]

Based on the curves shown in Fig. 3, the maximum heat that a Peltier needs to transfer from cold to hot side can be attained. Similarly, maximum voltage required to attain maximum cooling can be obtained based on Fig. 4.

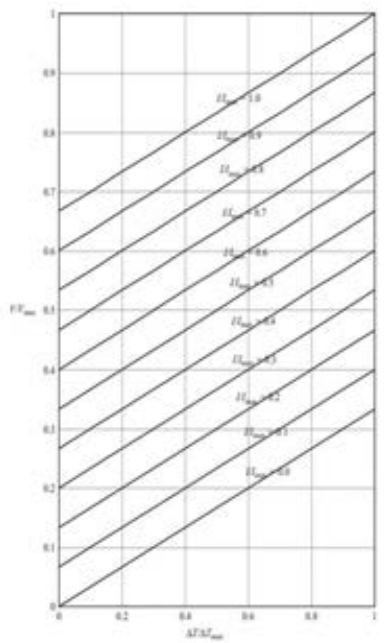

Fig 4. Universal charts of voltage rate ratio vs. temperature difference ratio for a single stage Peltier module.[9]

The values then obtained for $Q_{\max }, V_{\max }$ and $I_{\max }$ can be used for the selection of appropriate commercially available module.

\section{MATHEMATICAL MODELLING}

\section{A. Cold box with heat sink}

The insulating material considered for cold box is polystyrene of thermal conductivity $0.33 \mathrm{~W} / \mathrm{m} . \mathrm{K}$ and internal packing material is taken as plastic of $\mathrm{k}=0.2$ $\mathrm{W} / \mathrm{m} \cdot \mathrm{K}[11]$. Aluminum $(\mathrm{k}=240 \mathrm{~W} / \mathrm{m} \cdot \mathrm{K})$ heat sink is considered. The properties of air are taken at $45^{\circ} \mathrm{C}$. The dimensional view of the cold box with heat sink is as shown in Fig. 5.

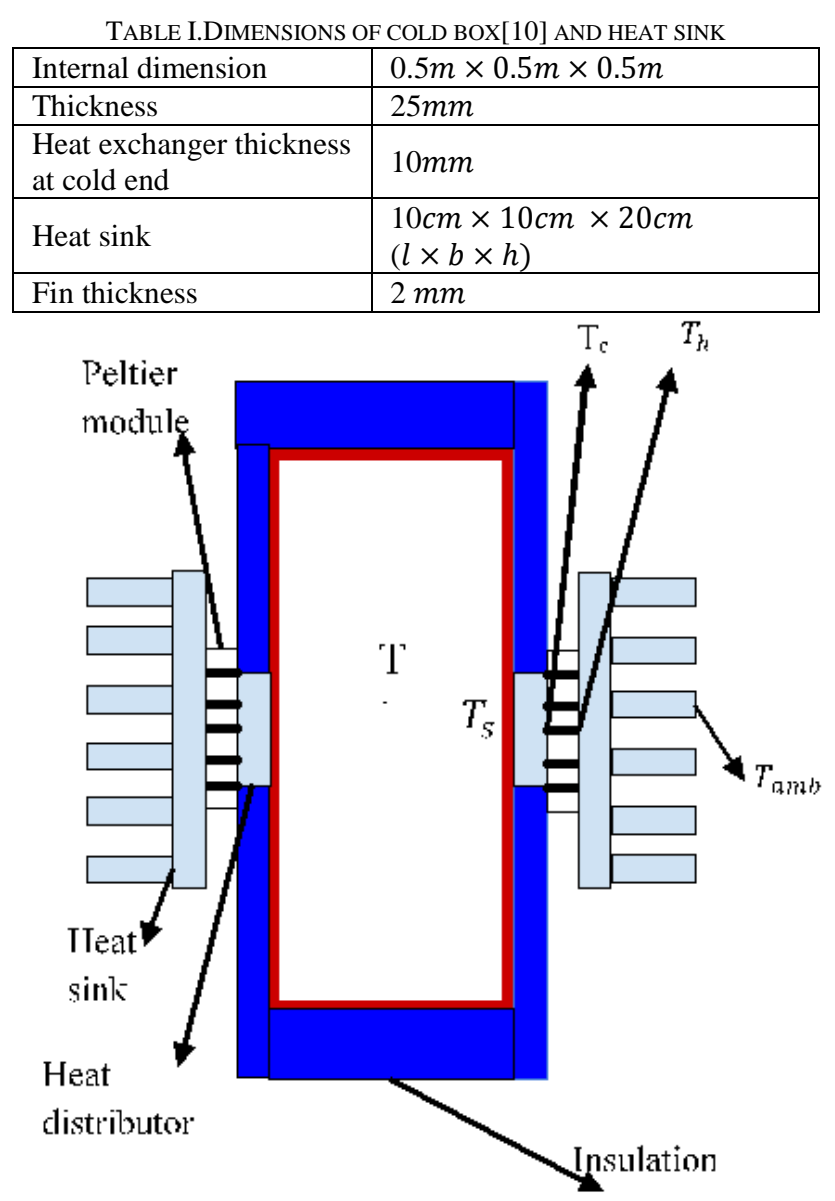

Fig 5 Two-dimensional view of the cold box with heat sink

\section{Assumptions}

The following assumptions are made for the design of thermoelectric module based cold box:

- No heat loss takes place to or from the system.

- Heat transfer takes place through the heat distributor only.

- Thermophysical properties such conductivity, resistivity etc. does not change with temperature.

- Material of the module be BISMUTH AND TELLURIDE for both $\mathrm{p}$ and $\mathrm{n}$ semiconductor[12].

In this study a heat load of $50 \mathrm{~W}$ is considered and an internal temperature of is $5^{\circ} \mathrm{C}$ is to be maintained.

\section{Calculations}

Internal convection in the cold box:

$Q=h A \Delta T$

Let the heat transfer coefficient of air inside the cold box is $5 \frac{W}{m^{2} k}$ and the temperature to be maintained in the cabin is $T_{\text {in }}=5^{\circ} \mathrm{C}$. 
Therefore the temperature at the boundary of the cabin inside wall is $T_{h}=1.7^{\circ} \mathrm{C}$

Conduction through the heat distributor:

$Q=k A \frac{\Delta T}{l}$

The area of cross section of heat distributor is taken as $50 \mathrm{~mm} \times 50 \mathrm{~mm}$ with thickness $(\mathrm{l})=10 \mathrm{~mm}$. Therefore the temperature at cold end of the module is $\mathrm{T}_{\mathrm{c}}=1.2^{\circ} \mathrm{C}$.

\section{a. Heat sink}

Let the velocity of the air flowing over the heatsink from the fan placed outside is $4 \mathrm{~m} / \mathrm{s}$

and the fin thickness to be $2 \mathrm{~mm}$

Then Reynolds number

$R e=\frac{v \times L_{c}}{v}$

Where $\quad L_{e}=$ characteristic length $(m)$.

Based on the above explanation, the calculated flow can be in laminar region.

$N u=\frac{h \times L_{c}}{K_{\text {air }}}$

Optimum spacing between the fins can be based on Eq (14) and obtained as $1.63 \mathrm{~mm}$

$Z_{\text {opt }}=3.24 \times L_{c} \times \operatorname{Re}^{\frac{-1}{2}} \times \operatorname{Pr}^{\frac{-1}{4}}$

Number of fins for the heat sink can be given by Eq. (15)

$N=\frac{w}{t+Z_{\text {opt }}}=\frac{100}{1.63+2}=28$

Area of each fin can be calculated as

$A_{f}=2(\mathrm{l}+\mathrm{t}) \mathrm{h}=0.0204 m^{2}$

Total area

$A_{t}=N\left(A_{f}+Z_{\text {opt }} \times l\right) \quad=0.575764 m^{2}$

Efficiency of the fin can be given by Eq. 16

$\eta_{f}=\frac{\tanh \left(b \times \sqrt{\frac{2 \times h}{K_{a l} \times t}}\right)}{\left(b \times \sqrt{\frac{2 \times h}{K_{a l} \times t}}\right)}$

Overall efficiency

$\eta_{o}=1-N\left(\frac{A_{f}}{A_{t}}\right)\left(1-\eta_{f}\right)=0.6979$

Resistance through the fins can be given as

$R_{f}=\frac{1}{\eta_{o} \times h \times A_{t}} \quad=0.072301 \mathrm{~K} / \mathrm{W}$

Resistance through the base of the heat sink is

$R_{b}=\frac{l}{k A}=\frac{5 \times 10^{-2}}{240 \times 10 \times 10 \times 10^{-4}}=0.0208\left(\frac{K}{W}\right)$

Overall resistance through the heat exchanger can be calculated as $\mathrm{R}$
$R=0.097313 \mathrm{~K} / \mathrm{W}$

Power input to the module:

$P=V \times I=72$ watts

Then total heat load at the hot end of each the module is obtained to be $97 \mathrm{~W}$.

Therefore, the temperature at the hot end of the module based onEq. 1

$$
T_{h}=51.6^{\circ} \mathrm{C}
$$

TABLE IV PROPERTIES OF THE THERMOELECTRIC MODULE[13]

\begin{tabular}{|l|c|c|}
\hline \multicolumn{3}{|c|}{ Properties of P and N semiconductors } \\
\hline Seebeck coefficient, $\alpha$ & $330 \times 10^{-6}$ & $\frac{V}{K}$ \\
\hline Electrical resistivity, $\rho$ & $\frac{1}{\left(3.055 \times 10^{3}\right)}$ & $\Omega \mathrm{cm}$ \\
\hline
\end{tabular}

By making use of the values obtained for $T_{n}$, the $\Delta T_{\max }$ can be calculated as $68{ }^{\circ} \mathrm{C}$.

Since a single stage Peltier module can achieve maximum temperature change about $68^{\circ} \mathrm{C}[6]$. Therefore, the ratio $\Delta \mathrm{T} /$ $\Delta \mathrm{T}_{\max }$ can be obtained as 0.74 .

Based on Eqs. 8 and 9, the maximum current $\left(I_{\max }\right)$ for maximum absorption of maximum heat load can be given as $I_{\max }=8$ amps

Then the ratio of $\frac{I}{I_{\max }}$ becomes0.75.

From the ratios obtained from $\Delta \mathrm{T} / \Delta \mathrm{T}_{\max }$ and $\frac{I}{I_{\max }}$, and by making use of Fig. 3, the ratio for $\frac{Q}{Q_{\max }}$, ,an be given as 0.2.

As the heat to be removed by a Peltier is $25 \mathrm{~W}$, the maximum heat load that a Peltier can transfer $\left(Q_{\max }\right)$ is 125W.

Also, by making use of Fig. $4, V_{\max }$ was obtained to be $20 \mathrm{~V}$.

\section{RESULTS AND DISCUSSION}

From the obtained values of $Q_{\max }, V_{\max }, I_{\max }$ and $\Delta T_{\max }$, a commercially available Peltier module can be selected.

The module which suits for the considered cold box with heatsink is given in Table $\mathrm{v}$.

TABLE V SPECIFICATION OF TEC1-12715

\begin{tabular}{|c|c|c|}
\hline Thermoelectric properties & Units & Value \\
\hline$I_{\max }$ & $\mathrm{A}$ & 15.6 \\
\hline$V_{\max }$ & $\mathrm{V}$ & 15.4 \\
\hline$\Delta T_{\max }$ & $\mathrm{K}$ & 68 \\
\hline Resistance & $\mathrm{ohm}$ & 0.80 \\
\hline$Q_{\max }$ & $\mathrm{W}$ & 150 \\
\hline
\end{tabular}




\section{A. Cold box without heatsink}

Total rate of heat to be transfer is 50W from the cold box. The temperature to be maintained is $5^{\circ} \mathrm{C}$ and ambient temperature is taken as $40^{\circ} \mathrm{C}$. From Fig. 5, by not considering heat sink, the thermal resistance network diagram for the cold box is shown in Fig.6.

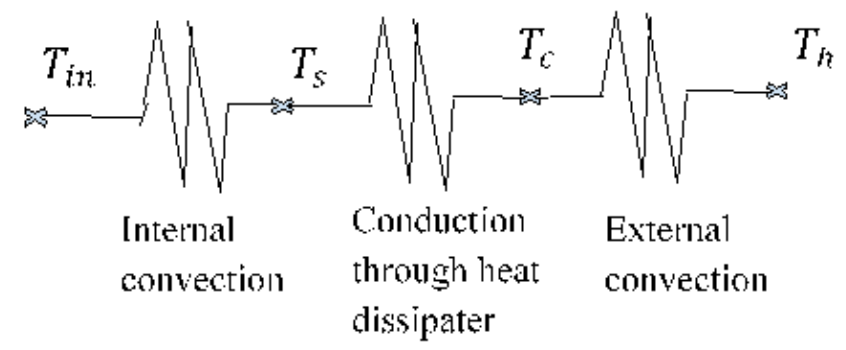

Fig 6. Thermal resistance network of the cold box without heatsink

Convective heat transfer inside the cold box is considered to by $5 \mathrm{~W} / \mathrm{m}^{2} \mathrm{~K}$.

From the Eq. 10, the temperature at the internal boundary of the cold box is $T_{s}=1.7^{\circ} \mathrm{C}$. The heat exchange by conduction from the cold side of the Peltier module can be given by Eq. 11. Based on which the temperature at cold end of the module can be $T_{c}=0.9^{\circ} \mathrm{C}$. Similarly, the hot end temperature of the module is $T_{h}=51.6^{\circ} \mathrm{C}$. Inline to this, the heat load to dissipate at the hot end of the module is $Q_{h}=97 \mathrm{~W}$.Based on the above, to maintain the required temperature at the hot and cold ends, the area can be calculated based on Eq. 20

$Q=h A \Delta T$

As discussed earlier, the heat transfer coefficient ' $h$ ' is taken as $10 \mathrm{~W} / \mathrm{m}^{2} \mathrm{~K}$, from which the required area can be obtained as $0.9615 \mathrm{~m}^{2}$.

If the surface area of the each module is taken as $50 \mathrm{~mm} \times 50 \mathrm{~mm}$ and to dissipate a heat load of $\mathrm{Q}_{\mathrm{h}}=97 \mathrm{~W}$ without heat sink, there will be a need of 384 modules.

\section{B. Discussion}

It may be noted that the thermoelectric modules are selected based on parameters viz. maximum amount of heat to be pumped $\left(\mathrm{Q}_{\max }\right)$, maximum amount of current $\left(\mathrm{I}_{\max }\right)$, maximum voltage $\left(V_{\max }\right)$ and maximum temperature difference $\left(\Delta T_{\max }\right)$. This maximum amount of heat $\left(\mathrm{Q}_{\max }\right)$ will be pumped at $\mathrm{I}_{\max }$ when $\Delta T=0$.

Conversely $\Delta T_{\max }$ is the maximum temperature difference achievable through the module at maximum current when heat load is zero. This implies that heat load and temperature difference are inversely proportional.

Therefore, for a given power input to the module as $\Delta T$ increases, heat pumping capacity decreases and if heat pumping capacity increases $\Delta T$ decreases. In this study the minimum value for the temperature difference is the difference between inside temperature of the cold box and ambient temperature outside the cold box. It can be noted that the actual value of the $\Delta T$ is greater than the difference between the hot and cold sides of the module.

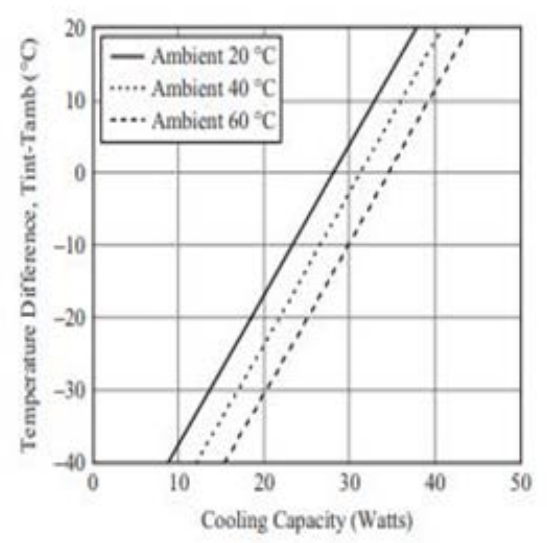

Fig 7. Performance graph [9]

Fig. 6 shows the performance curves for a module with the variation of temperature difference at different ambient temperatures. Thermoelectric module has their own physical limitation for attaining the maximum temperature difference. For a single stage Peltier module the maximum temperature difference that can be attained is $68^{\circ} \mathrm{C}$ across the elements. In order to achieve more temperature difference across the module one has to stack more modules one over the other. In case of a single stage thermoelectric module, the temperature difference increases 2 to 3 times that of the single one. Therefore, by stacking more number of the module, larger $\Delta T_{\max }$ can be achieved at lower $Q_{\max }$.

\section{CONCLUSION}

The present work is aimed to provide a methodology for selecting a proper thermoelectric module for the portable cold box which is to be maintained at required low temperature.

Based on the study, the temperature of about ${ }^{\circ} \mathrm{S}$ could be maintained in the cold box of $0.5 \mathrm{~m} \times 0.5 \mathrm{~m} \times$ $0.5 \mathrm{~m}$ dimension by removing the heat load of $50 \mathrm{~W}$ using the thermoelectric Peltier module and heat sinks. The module selected is capable of removing the maximum heat load of $150 \mathrm{~W}$ at rated voltage of $15.4 \mathrm{~V}$ and a current of 15.6 Amps. Further to maintain the same hot and cold end temperatures without heat sink, a very large surface area of $0.9615 \mathrm{~m}^{2}$ will be needed. The increase in surface area of the module will end up in increase in number of Peltiers.

For the best design of thermoelectric cooler, it is required to select the thermoelectric module with $Q_{\max }$ which has at least of 2 times that of $Q_{\text {total }}$, and an operating current of below $I_{\max }$. Also, the performance of the heat sink can be improved by placing the heat sink (i.e. by increasing the heat dissipation area) and by placing fins (increase the heat transfer coefficient) at the hot side of the Peltier. 


\section{REFERENCES}

\section{Nomenclature}

\section{APPENDIX}

\begin{tabular}{|c|c|}
\hline$A$ & Surface area of the cold box $\left(\mathrm{m}^{2}\right)$ \\
\hline$A_{e}$ & $\begin{array}{l}\text { Area of cross section of the thermocouple element } \\
(\mathrm{cm})\end{array}$ \\
\hline$A_{f}$ & Area of the fin \\
\hline$A_{t}$ & Total area of the fins \\
\hline$h$ & Local heat transfer coefficient of air $\left(\mathrm{W} / \mathrm{m}^{2} \mathrm{k}\right)$ \\
\hline$I$ & Current through the module (amps) \\
\hline$I_{m a}$ & Optimum current for maximum cooling rate (amps) \\
\hline$k$ & $\begin{array}{l}\text { Thermal conductivity of the of heat exchanger } \\
\text { material }(\mathrm{W} / \mathrm{m} \cdot \mathrm{K})\end{array}$ \\
\hline$L e$ & Length of the thermocouple element $(\mathrm{cm})$ \\
\hline$N$ & Number of fin in the heat sink \\
\hline$P_{\text {in }}$ & Input electrical power to the module (watts) \\
\hline $\operatorname{Pr}$ & Prandle number \\
\hline$Q$ & Heat load (W) \\
\hline $\begin{array}{l}Q_{a} \\
\text { ctiv }\end{array}$ & Active heat load (W) \\
\hline$Q_{c}$ & Heat absorbed at the cold end of the module (W) \\
\hline$Q_{h}$ & Heat released at the hot end of the modules (W) \\
\hline Q & $\begin{array}{l}\text { Maximum heat load that can be absorbed at the } \\
\text { cold end of the module (W) }\end{array}$ \\
\hline$R$ & Thermal resistance of the heat exchanger $\left({ }^{\circ} \mathrm{C} / \mathrm{W}\right)$ \\
\hline $\mathrm{R}$ & Module resistance (ohms) \\
\hline $\operatorname{Re}$ & Reynolds number \\
\hline $\begin{array}{c}T_{a} \\
m b\end{array}$ & Ambient temperature of the surroundings $\left({ }^{\circ} \mathrm{C}\right)$ \\
\hline$T_{c}$ & The cold end temperature of the module $\left({ }^{\circ} \mathrm{C}\right)$ \\
\hline$T_{h}$ & The hot end temperature of the module $\left({ }^{\circ} \mathrm{C}\right)$ \\
\hline $\begin{array}{c}T_{m} \\
a x\end{array}$ & $\begin{array}{l}\text { Most efficient temperature difference between the } \\
\text { hot and cold side of the module }(\mathrm{k})\end{array}$ \\
\hline$V_{m}$ & $\begin{array}{l}\text { Maximum input voltage at an optimum input } \\
\text { current (volts) }\end{array}$ \\
\hline$\overline{V_{m}}$ & Voltage applied (volts) \\
\hline$Z_{o}$ & Optimum spacing between the fins \\
\hline$\alpha$ & Seebeck coefficient (volt/kelvin). \\
\hline $\begin{array}{c}\Delta T \\
1 \\
\end{array}$ & $\begin{array}{l}\text { Temperature difference between the surrounding } \\
\text { and temperature to be maintained in the cold box } \\
\left({ }^{\circ} \mathrm{C}\right)\end{array}$ \\
\hline $\begin{array}{c}\Delta T \\
2\end{array}$ & $\begin{array}{l}\text { Temperature difference between surrounding and } \\
\text { hot end of the module }\left({ }^{\circ} \mathrm{C}\right)\end{array}$ \\
\hline$\eta_{f}$ & efficiency of the fin \\
\hline$\eta_{o}$ & Overall efficiency of the fins \\
\hline$\rho$ & $\begin{array}{l}\text { Thermal resistivity of the thermocouple element } \\
(\Omega . \mathrm{cm})\end{array}$ \\
\hline
\end{tabular}

[1] WHO, "Making use of Vaccine Vial Monitors Flexible vaccine management for polio," pp. 19, 2000.

[2] F. Application, P. Data, P. E. J. Carone, R. Cited and U. S. P. Documents, “United States Patent (19)," 1996.

[3] E. On, U. S. E. Of, T. Devices, and F. O. R. E. Cooling, "Ipack200733154 Evaluation on Use of Thermoelectric Devices for Electronics Cooling," in proceedings of the ASME InterPack Conference--2007, pp. 1-5, 2007.

[4] P. G. Manoj V Murhekar,Srihari Dutta,Ambujam Nair KapoorSailaja Bitragunta and Raja Dodum, "WHO | Frequent exposure to suboptimal temperatures in vaccine cold-chain system in India: results of temperature monitoring in 10 states,” WHO, 2013. [Online]. Available: http://www.who.int/bulletin/volumes/91/12/13-119974$\mathrm{ab} / \mathrm{en} /$.

[5] S. Kumar, A. Gupta, G. Yadav and H. P. Singh, "Embedded System," in International Conference on Recent Developments in Control, Automation and Power Engineering (RDCAPE), No. 3, pp. 314-319, 2015.

[6] C. N. Kim and J. Kim, "Numerical Examination of the Performance of a Thermoelectric Cooler with Peltier Heating and Cooling," $J$. Electron. Mater.,Vol. 44, No. 10, pp. 3586-3591, 2015.

[7] V. Egan, J. Stafford, P. Walsh and E. Walsh, "An Experimental Study on the Design of Miniature Heat Sinks for Forced Convection Air Cooling,” J. Heat Transfer, Vol. 131, No. 7, pp. 071402, 2009.

[8] S. B. Riffat and X. Ma, "Improving the coefficient of performance of thermoelectric cooling systems: A review,” Int. J. Energy Res., Vol. 28, No. 9, pp. 753-768, 2004.

[9] H. S. Lee, "Thermal Design: Heat Sinks, Thermoelectrics, Heat Pipes, Compact Heat Exchangers, and Solar Cells," in THEREMAL DESIGN, 1st Ed., I. JOHN WILEY \&SONS, Ed. 2010, pp. 34, 100, 102.

[10] P. M. Teertstra, M. M. Yovanovichand J. R. Culham, "Modeling of Natural Convection in Electronic Enclosures," J. Electron. Packag.,Vol. 128, No. 2, pp. 157, 2006.

[11] S. B. Riffat, S. A. Omer and X. Ma, "A novel thermoelectric refrigeration system employing heat pipes and a phase change material: An experimental investigation,” Renew. Energy, Vol. 23, No. 2, pp. 313-323, 2001.

[12] L. T. Dang et al., "Thermoelectric Micro-Refrigerator Based on Bismuth/Antimony Telluride,” J. Electron. Mater.,Vol. 46, No. 6, pp. 3660-3666, 2017.

[13] H. J. Goldsmid, "Bismuth telluride and its alloys as materials for thermoelectric generation," Materials (Basel)., Vol. 7, No. 4, pp. 2577-2592, 2014. 